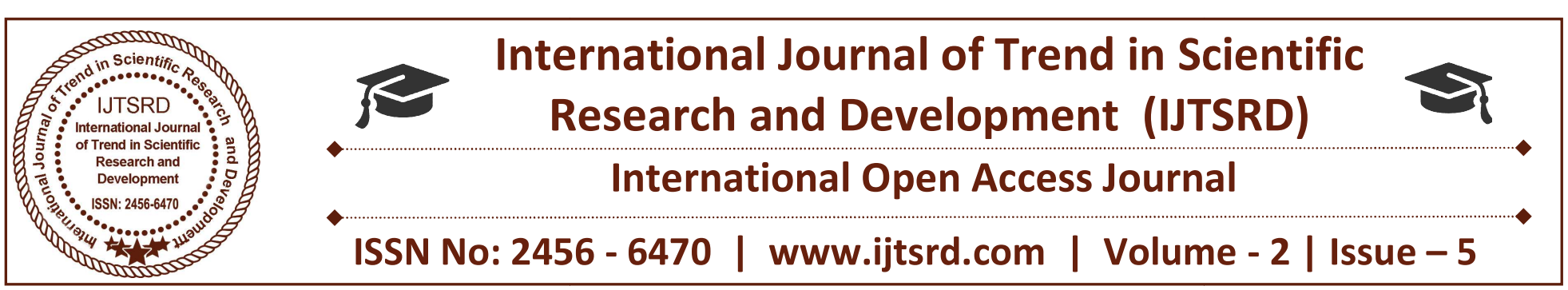

\title{
Comparative Study of Strength of Fibre Reinforced Geo polymer Concrete and Conventional (OPC) Concrete
}

\author{
Shah N A \\ Student, Department of Civil Engineering, \\ RMD Sinhgad School of Engineering, Warje, Pune, Maharashtra, India
}

\begin{abstract}
Concrete is the world's most versatile, reliable and durable construction material. Concrete is the most used material, which requires large quantities of Portland Cement for its production. Ordinary Portland Cement production is the second major generator of carbon dioxide after automobile industry. In addition to that, large amount of energy is consumed for cement production. Hence, it is inevitable to find an alternative material to the most expensive and resource consuming Portland Cement. / Geo polymer concrete is a futuristic construction material which is produced by the chemical action of inorganic molecules. Geo polymer concrete is produced without using any amount of ordinary portland cement. This geo polymer concrete has been studied vastly/by many researchers in the past decade and studies suggest that geo polymer concrete is supreme to conventional cement concrete from structural as well as durability point of view. But it still suffers from a major drawback that it requires accelerated curing for its high early strength gain. In this research, the effect of introduction of various types of fibres on the compressive strength and split tensile strength of geo polymer concrete is been studied and comparison is done with conventional (OPC) concrete.
\end{abstract}

Keywords: Fibre Reinforcement ,Geo polymer Concrete, Sodium Silicate, Sodium Hydroxide, Fly Ash

\section{INTRODUCTION}

Geo polymer concrete is a concrete in which the binder is entirely replaced by an inorganic polymer formed between a strong alkaline solution and an alumina silicate source. The quantity and ratio of alkaline solution used can affect the concrete strength and curing time. Alumino-silicate sources are not

restricted to red-mud, fly-ash, blast furnace slag and kaolin. The variability of geo polymer binder and activator increase the difficulty to manufacture a homogenous and universal geo polymer concrete standard. Carbon emissions can be significantly reduced by using alumina silicate geo polymer binders instead of Portland cement. Compared to Portland cement, fly-ash based geo polymer concrete reduce carbon emissions by $80 \%$ which has the potential to reduce global emissions by approximately 2.1 billion tonnes a year. This is equivalent to taking two thirds of global traffic off the road each year.

Geo polymer is essentially a cement free concrete. This material is being studied extensively and shows promise as a greener substitute for ordinary Portland cement concrete. This project presents the results from studies on mix design development to enhance workability and strength of geo polymer concrete. The report also includes brief details of effect of fibres when added to concrete.

\section{LITERATURE REVIEW}

N A Lloyd and B V Rangan (2010) presented brief details of fly ash-based geo polymer concrete and a simple method to design geo polymer concrete mixtures. They also stated that Geo polymer concrete has excellent properties and is well-suited to manufacture precast concrete products that are needed in rehabilitation and retrofitting of structures after a disaster. The economic benefits and contributions of geo polymer concrete to sustainable development were also been outlined. 
Raijiwala D.B and Patil H. S (2011)concluded that compressive strength of GPC increases over controlled concrete by 1.5 times (M-25 achieves M45).Split Tensile Strength of GPC increases over controlled concrete by 1.45 times. Flexural Strength of GPC increases over controlled concrete by 1.6 times.

Ganapati Naidu. P et al. (2012) made an attempt to study strength properties of geo polymer concrete using low calcium flyash replacing with slag in 5 different percentages. Sodium silicate $(103 \mathrm{~kg} / \mathrm{m} 3)$ and sodium hydroxide of 8 molarity $(41 \mathrm{~kg} / \mathrm{m} 3)$ solutions were used as alkalis in all 5 different mixes. With maximum (28.57\%) replacement of flyash with slag, achieved a maximum compressive strength of $57 \mathrm{MPa}$ for 28 days. The same mix showed $43.56 \mathrm{MPa}$ after exposure of $500^{\circ} \mathrm{C}$ for 2 hours.

B J Mathew et al. (2013) presented the effect of replacement of fly ash with bottom ash at varying percentage on strength of Geo polymer concrete. The effect of curing methodology on strength of fly ashGGBS based geo polymer concrete was also been evaluated. Economic impact and sustainability studies were conducted on both OPC based concrete and geo polymer concrete which showed that the geo polymer concrete can be prepared at comparable cost with that of OPC concrete and also offer huge reduction in carbon dioxide emissions.

L. MariaSubashini, Shamini Valentina (2015) have carried out the tests on fibre reinforced concrete for various strength like compression, flexural, split tensile strength on the specimens by Destructive and Non Destructive Testing. Fiber reinforced concrete (FRC) is concrete containing fibrous material which increases its structural integrity. Fibre is discrete material having some characteristic properties. Polypropylene is one of the cheapest and abundantly available polymers. Polypropylene fibers are resistant to most chemical attacks and also reduces water permeability, controls cracking, reduces rebound loss and increases flexibility.

A. Pavani et al. (2016) carried out an experimental investigation to study the material and mixture proportions; the manufacturing processes, the fresh and hardened state characteristics of fly ash based geo polymer concrete to evaluate the compression behaviour of geo polymer concrete. The behaviour was found to be considerably more than that of conventional concrete.

\section{EXPERIMENTAL PROGRAMME}

Casting of cubes and cylinders on conventional as well as geo polymer concrete with same proportion of various types of fibres in the mixhave been carried out. The aspect ratio of fibres was also kept constant. The mix design and casting process for conventional concrete has not been discussed in this paper as it very well known. However the mix design, preparation, casting and curing of GPC has been discussed in detail in the later sections.

\section{A. Mix Design}

For design of geo polymer concrete generally some performance criterion are selected. Some guidelines for the design geo polymer concrete have been proposed by previous researchers. The design criteria of geo polymer concrete mixture depends on the application. For clarity, the compressive strength of hardened concrete and work ability of fresh concrete are considered as performance criteria. Tomeet this criteria, water to geo polymer solids ratio by mass, the alkaline liquid to fly ash by mass, the heat curing temperature and curing time are selected as the parameters.

To obtain a strength of $45 \mathrm{Mpa}$ concrete mix was designed assuming the density of geo polymer concrete as $2400 \mathrm{~kg} / \mathrm{m}^{3}$ when aggregates are in saturated surface dry condition. The combined mass of aggregates is taken as $77 \%$ of the mass of concrete i.e equal to $1848 \mathrm{~kg} / \mathrm{m}^{3}$.

The aggregates were taken to match the standard grading curves used in design of portland cement concrete and were modified by trial and error to get a uniform and workable mix. The ratio of coarse to fine aggregates was taken as 1.20 and hence Fine Aggregates equal to $840 \mathrm{~kg} / \mathrm{m}^{3}$; and Coarse aggregates equal to $1008 \mathrm{~kg} / \mathrm{m}^{3}$.

The mass of low calcium fly ash and alkaline liquid equal to $522 \mathrm{~kg} / \mathrm{m}^{3}$.Using Alkaline liquid to fly ash ratio by mass as 0.35 , the mass of fly ash equal to 408 $\mathrm{kg} / \mathrm{m}^{3}$ and the mass of the alkaline liquid equal to $144 \mathrm{~kg} / \mathrm{m}^{3}$. From the recommendations of the previous researchers the ratio of Sodium Silicate solution to Sodium Hydroxide solution by mass is taken as 2.5. Therefore the mass of Sodium Hydroxide solution 
equal to $41 \mathrm{~kg} / \mathrm{m}^{3}$. Hence, mass of sodium silicate solution equal to $103 \mathrm{~kg} / \mathrm{m}^{3}$.

The alkali activator solutions used were sodium silicate and sodium hydroxide. Sodium silicate solution comprising $\mathrm{Na}_{2} \mathrm{O}=13.72 \%, \mathrm{SiO}_{2}=34.16 \%$ and $\mathrm{H}_{2} \mathrm{O}=52.12 \%$ by mass was used. The sodium hydroxide dry pellets having $97 \%$ purity were used. 8 Molar NaOHsolution was prepared by adding water to the dry pellets. This solution comprises about $74 \%$ water and $26 \%$ dry pellets. To adjust the water to geo polymer solids ratio the following calculations are done:

I. In sodium silicate solution, amount of water equal to $53.68 \mathrm{~kg} / \mathrm{m}^{3}$; and solids equal to 46.32 $\mathrm{kg} / \mathrm{m}^{3}$.

II. In $8 \mathrm{M}$ sodium hydroxide solution, amount of water equal to $30.34 \mathrm{~kg} / \mathrm{m}^{3}$; and solids equal to $10.66 \mathrm{~kg} / \mathrm{m}^{3}$.

Thus, total water equals to $84.02 \mathrm{~kg} / \mathrm{m}^{3} \& \mathrm{Geo}$ polymer solids equal to $464.98 \mathrm{~kg} / \mathrm{m}^{3}$. Hence water to geo polymer solids ratio equals to 0.181 . But according to the design chart we need a water to geo polymer solids ratio of 0.19 for a compressive strength of $45 \mathrm{Mpa}$. Thus the total water needed equals to 464.98 x $0.19=88.35 \mathrm{~kg} / \mathrm{m}^{3}$. Thus extra water required to be added is $88.35-84.02=4.33 \mathrm{~kg} / \mathrm{m}^{3}$.

From workability considerations, no loss of compressive strength results with use of super plasticizer upto $4 \%$ by mass of the source material. Hence, taking super plasticizer about $2 \%$ by weight of fly ash which equals to $8.16 \mathrm{~kg} / \mathrm{m}^{3}$.

Table 1- Final Mix Proportions for GPC

\begin{tabular}{|c|c|c|}
\hline $\begin{array}{c}\text { Sr. } \\
\text { No }\end{array}$ & Materials & Quantity $\left(\mathbf{k g} / \mathbf{m}^{\mathbf{3}}\right)$ \\
\hline $\mathbf{1}$ & $\begin{array}{c}\text { Coarse Aggregates } \\
(20 \mathrm{~mm})\end{array}$ & 1008 \\
\hline $\mathbf{2}$ & $\begin{array}{c}\text { Fine Aggregates } \\
(10 \mathrm{~mm})\end{array}$ & 840 \\
\hline $\mathbf{3}$ & Fly Ash (class 'F') & 408 \\
\hline $\mathbf{4}$ & 8 M NaOH solution & 41 \\
\hline $\mathbf{5}$ & $\begin{array}{c}\text { Sodium Silicate } \\
\text { solution }\end{array}$ & 103 \\
\hline $\mathbf{6}$ & Extra water & 4.33 \\
\hline $\mathbf{7}$ & Super-Plasticizer & 8.16 \\
\hline
\end{tabular}

\section{B. Preparation of Alkaline Solution}

To prepare 8 Molar sodium hydroxide solution, 320 grams of dry sodium hydroxide pellets are dissolved in 1 litre of water. The sodium hydroxide solution was prepared 24 hours prior to casting so as to allow it to react with water and the reaction being exothermic in nature, releases a lot of heat. Just about 30 minutes before casting, sodium silicate solution was added to the sodium hydroxide solution and stirred well.

\section{Mixing and casting Procedure}

Firstly the dry contents including the fine and coarse aggregates and the source material fly-ash were dry mixed for about 2-3 minutes in a mixer. After dry mixing the alkali activators solutionand superplasticizer were added in 2 to 3 installments and the wet mixing was carried out for about 4-5 minutes. The concrete after mixing was uniform and stiff and was a bit tougher to handle compared to conventional concrete.It was then filled into the standard $150 \mathrm{~mm}$ cube moulds and $150 \mathrm{~mm} \times 300 \mathrm{~mm}$ cylinders in three layers and compacted 60 times per layer (as per recommendations of Hardjto et.al., 2005) using the $16 \mathrm{~mm}$ dia. tamping rod. The surface was finished with the help of a trowel and the cubes andcylinders were then allowed to rest in ambient atmosphere for a period of 24 hours. After the so called 'rest period' of 24 hours it was found that the concrete was not completely set and so the specimens along the mouldswere placed in the oven for curing.

\section{D. "Curing}

Heat curing of geo polymer concrete is recommended by previous researchers. Strength of geo polymer concrete is influenced by curing time and temperture. The temperature of oven was set to $60^{\circ} \mathrm{C}$ for 24 hours after which specimens were kept in ambient temperature for curing.

\section{TESTS, RESULTS AND DISCUSSIONS}

In the following section test results for compressive strength and split tensile strength of geo polymer concrete and conventional (OPC) concrete have been compared at 7 days and 28 days by adding fibres to concrete. 
International Journal of Trend in Scientific Research and Development (IJTSRD) ISSN: 2456-6470

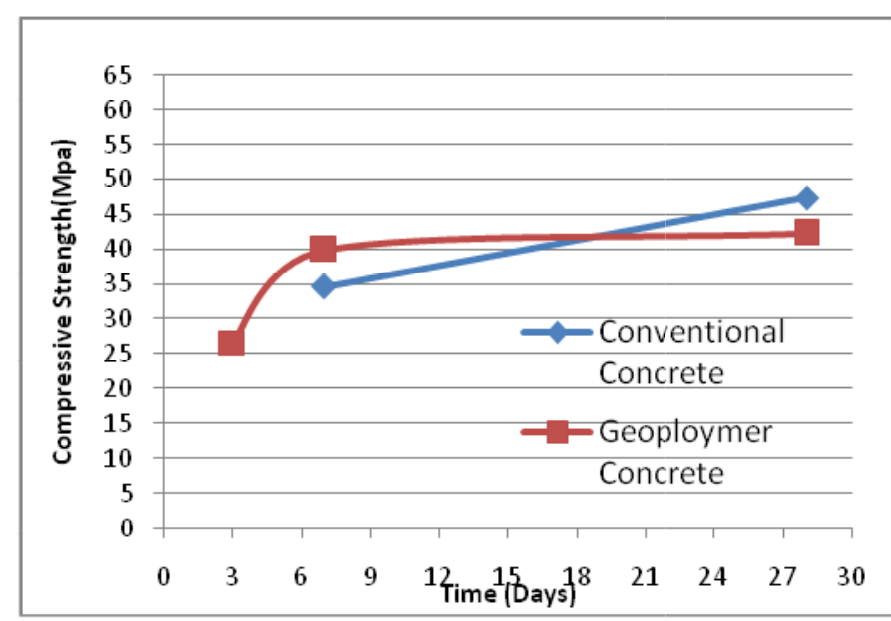

Fig.1Comparison of Geo polymer concrete and Conventional concrete without fibre

From Fig.1, we can see that the conventional cement concrete gains strength progressively upto 28 days where asgeo polymer concrete shows high early strength gain in the initial stages upto 7 days after which the strength gain is almost negligible.

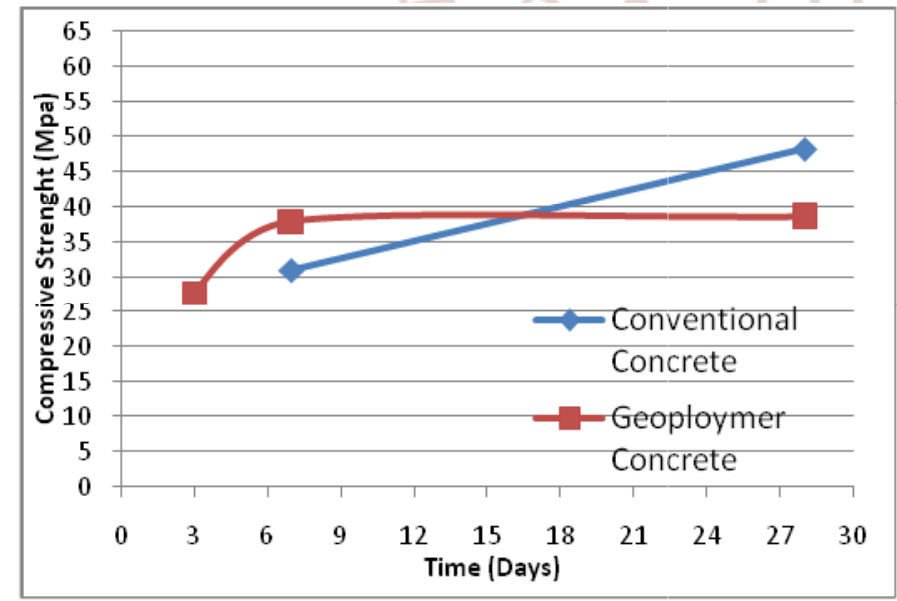

Fig.2Comparison of Geo polymer concrete and

Conventional concrete with Polypropylene Fibres

From Fig.2we can conclude that Geo polymer concrete gains early high strength during 3 to 7 days.' Conventional Concrete keeps on gaining strength after 7 days whereas Geo polymer Concrete slows down in attaining strength after 7 days. There is not much of difference noticed in strength of 7 days and 28 days in Geo polymer Concrete after using Polypropylene fibres.

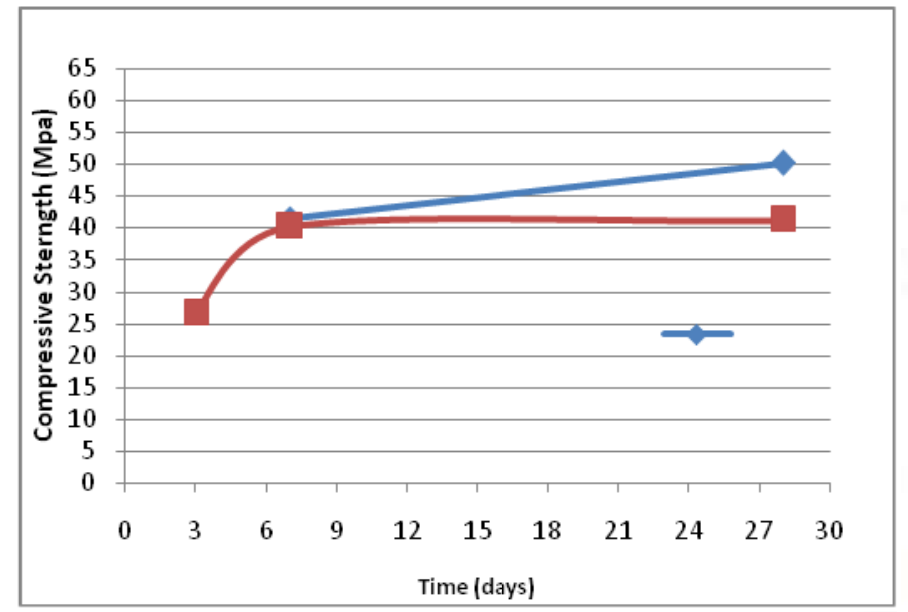

Fig.3Comparison of Geo polymer concrete and Conventional concrete with Steel Fibres

From Fig.3we can conclude that Geo polymer concrete gains early high strength during 3 to 7 days. Conventional Concrete keeps on gaining strength after 7 days whereas Geo polymer Concrete slows down in attaining strength after 7 days. There is a minute difference in 7 days strengths of both concrete using Steel fibres.

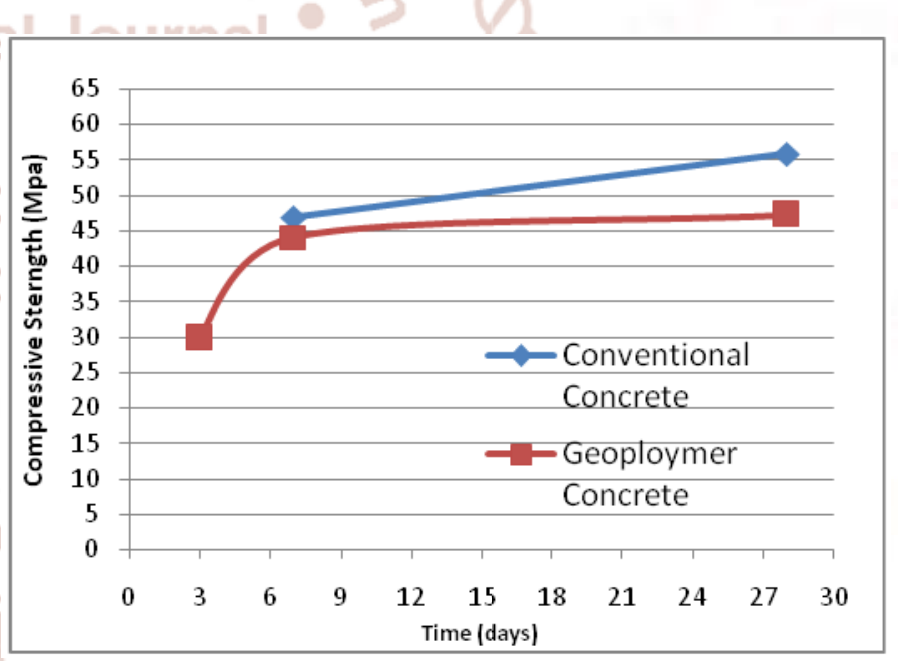

Fig.4Comparison of Geo polymer concrete and Conventional concrete with Glass Fibres

From Fig.4we can conclude that Geo polymer concrete gains early high strength during 3 to 7 days whereas Conventional Concrete keeps on attaining the strength after 7 days. There is a slight difference in strengths of 7 days and 28 days in Geo polymer Concrete even after the use of Glass fibres. There is a minute difference in 7 days strength of both concrete using Glass fibres. The 7 days and 28 days strength in Geo polymer Concrete is less than Conventional Concrete using Glass fibres. 
International Journal of Trend in Scientific Research and Development (IJTSRD) ISSN: 2456-6470

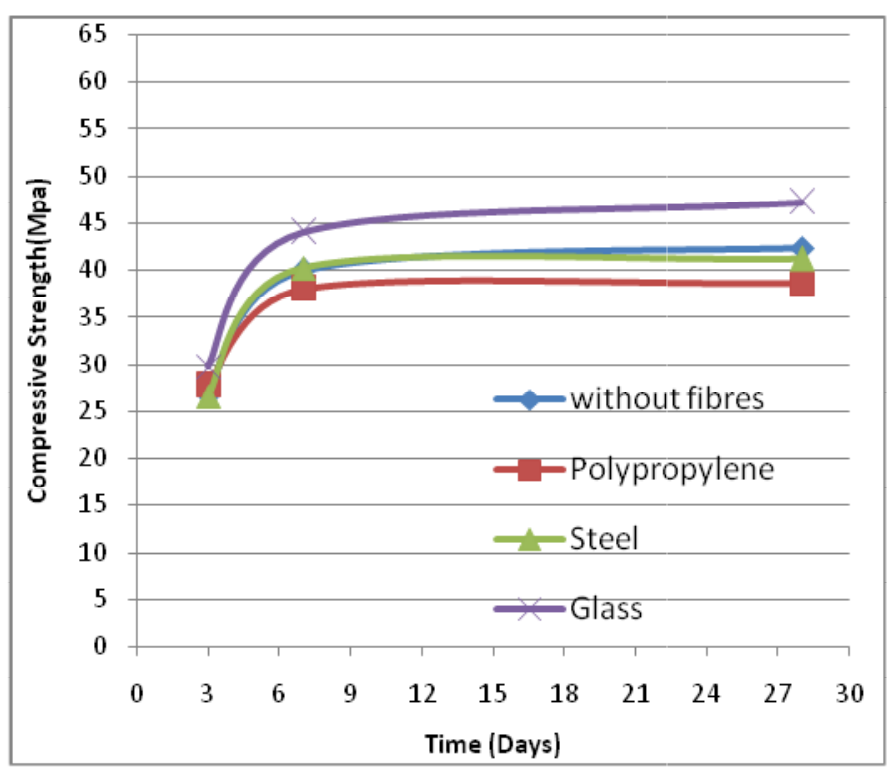

Fig.5Comparison graph showing effect of fibres on Compressive strength of Geo polymer concrete

From Fig.5we can compare compressive strength of geo polymer concrete with various types of fibres at 3 , 7 and 28 days. We can conclude that use of glass fibres is giving a remarkable increase in compressive strength compared to other fibres. Using glass fibres is leading to an increase in compressive strength by about $18 \%$.

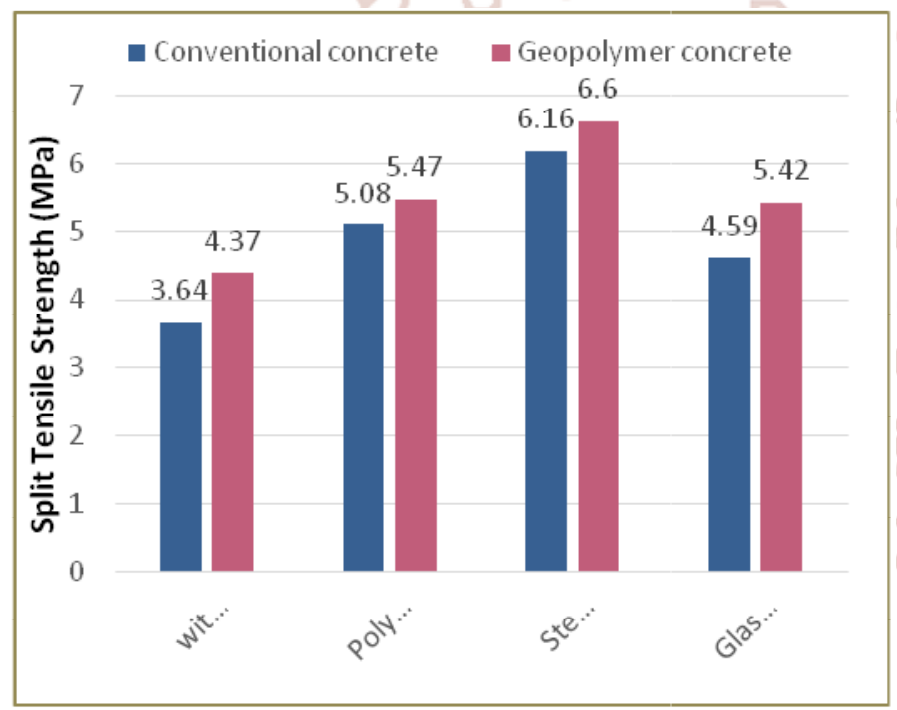

Fig.6 Comparison of Split Tensile Strength of Conventional concrete to Geo polymer concrete with various fibres

From Fig.6 we can conclude that the Split Tensile Strength of Geo polymer concrete is more as compared to Conventional Concrete. The difference between the strengths is almost constant in comparison of all types of fibres. It can be seen from the chart that use of steel fibres are giving remarkable increase in tensile strength of Geo polymer concrete.

\section{CONCLUSIONS}

1. Water to geo polymer solids ratio for geo polymer concrete is similar to water cement ratio in cement concrete and is the main parameter governing the strength of geo polymer concrete mix.

2. Geo polymer concrete is susceptible to climate changes while carrying out the mixing process. Hence, care must be taken while experimental work, to carry out the casting at location where there is not much variation in temperature and humidity with change in atmospheric condition.

3. The final setting time of geo polymer concrete is quite long when compared to conventional concrete. Even after 24 hours of exposure to ambient atmosphere, it does not set completely.

4. The process of geo polymerization is quite faster than the hydration of cement concrete and almost total design strength of the mix is achieved in 7 days after which the gain in strength is negligible.

5. Another important parameter affecting the strength gain of the geo polymer concrete is the curing regime. Care must be taken to keep the samples in oven for curing upto predetermined time period and temperature only.

6. The compressive and split tensile strength of cement concrete and geo polymer concrete are affected in similar manner by the use of various kinds of fibres.

7. Similar to cement concrete, even geo polymer concrete is relatively weak in tension. The indirect tensile strength obtained is about $10 \%$ of the compressive strength.

\section{A. Recommendations for future research}

Many researchers appeal geo polymer concrete as the concrete of the new age and consider as a potential replacement for the conventional cement concrete due to its reduced environmental impact. But there are still many major limitations to implementing wide use of geo polymer concrete in construction practices. The main drawback of geo polymer concrete is requirement of elevated temperature for curing without which it does not set and gain strength soon enough. The challenge for the coming generation or researchers would be finding a way to eliminate this drawback so that geo polymer concrete can find an even wider application base like use for construction of buildings and other large structures rather than only road construction and repairing purposes. 
There are a lot of waste materials other than fly ash which have cementitious properties and can be put to use in creating geo polymer concrete. Also the costly alkali activator solutions may be replaced by combinations of some other chemicals to cut the cost of the geo polymer concrete.

Coming to the mix design aspect, many researchers have worked over years on developing a rational mix design process for geo polymer concrete. But still the results do not resemble the actual design and still a lot of research work is needed to be carried out. In a country with a hot climate like India geo polymer concrete can be used advantageously for its application inprecasting industry. Unfortunately there is no standard code developed for Geo polymer concrete mix design, but if encouragement is to be given for use of such eco friendly concrete, efforts will be required to put forward code of practice for design and usage of Geo polymer concrete.

\section{ACKNOWLEDGMENT}

We express our gratitude to our principal Dr. C B BANGAL and HOD Prof. R. D. SHINDE for supporting us in completing our project work successfully by providing the required facilities and assurance. We are also grateful toMr.RaghuveerJambhale and Shree Shankeshwar Construction for giving us the opportunity to carry out experimental programme of this research at their site. We would also like to thank the staff at Shree Shankeshwar Construction who have helped us throughout casting and testing of the samples at their laboratory.

\section{REFERENCES}

1. N.A Lloyd and B.V.Rangan; Geo polymer concrete with Fly-ash; Second International Conference on Sustainable Construction Materials and Technologies, June 28 to June 30, 2010, Italy.

2. M.W. Ferdous*, O. Kayali and A. Khennane; $A$ Detailed Procedure of Mix Design for Fly Ash Based Geo polymer Concrete; Fourth Asia-Pacific Conference on FRP in Structures (APFIS 2013) 11-13 December 2013, Melbourne, Australia.

3. Rekha K P ,Hazeena R; Strength and Durability of Fibre Reinforced Geo polymer Concrete; International Journal of Scientific \& Engineering Research, Volume 5, Issue 7, July 2014; ISSN 2229-5518.

4. Nisha Khamar, Resmi V Kumar; Properties of Hybrid Fibre Reinforced Geo polymer Concrete under Ambient Curing; International Journal of Science and Research (IJSR),Volume 4, Issue 8, August 2015;ISSN (Online): 2319-7064.

5. L. MariaSubashini, ShaminiValentina; $A$ Study on Comparison of Strength Properties of Fibre Reinforced Concrete; International Journal of Innovative Research in Science, Engineering and Technology ,Vol. 4, Issue 4, April 2015.

6. J. Thaarrini and S.Dhivya;Comparative Study on the Production Cost of Geo polymer and Conventional Concrete; International Journal of Civil Engineering Research. ISSN 2278-3652 Volume 7, Number 2 (2016), pp. 117-124.

7. A. Pavani et al.;Conventional Concrete Over Geo Polymer Concrete Using GGBS; International Journal of Engineering and Applied Sciences (IJEAS) ISSN: 2394-3661, Volume-3, Issue-4, April 2016. 